\title{
Remissão espontânea de um granuloma eosinofílico orbitário após biópsia - Relato de caso e revisão da literatura
}

Spontaneous remission of an orbital eosinophilic granuloma after biopsy - $\mathcal{A}$ case report
and literature review

Jayter Silva de Paula ${ }^{1}$

Fernando Chafud ${ }^{1}$

Antonio Augusto Velasco e Cruz

\section{RES UMO}

Objetivo: Relatar o caso de paciente de 17 anos de idade com granuloma eosinofílico (GE) na parede superior da órbita com regressão espontânea após biópsia. Métodos: Relato de caso. Resultados: Remissão espontânea após biópsia incisional, via palpebral, de lesão de teto orbitário, sem evidências clínicas e tomográficas de recorrência com seguimento de 22 meses. A análise histopatológica da biópsia confirmou granuloma de aspecto proliferativo apresentando macrófagos, eosinófilos e células de Langerhans sem características neoplásicas. Conclusão: A remissão espontânea do caso descrito levanta a hipótese de que seguimento cuidadoso de pacientes com GE orbitário, confirmado por biópsia incisional, com exames de controle rotineiros, pode ser uma maneira menos invasiva e eficaz de abordagem.

Descritores: Granuloma eosinófílo; Histiocitose de células de Langerhans; Doenças orbitárias/patologia; Biópsia; Relato de caso; Adolescente

\section{INTRODUÇÃO}

O granuloma eosinofílico (GE) é uma doença rara, de etiologia pouco conhecida, que, geralmente, se apresenta com lise óssea localizada ou múltipla. Essa condição faz parte de um conjunto de síndromes denominado de histiocitose de células de Langerhans (HCL). No passado, as diferentes formas de apresentação da HCL eram coletivamente denominadas de Histiocitoses X. Distinguia-se o GE, a doença de Letterer-Siwe e uma terceira síndrome, denominada de Hand-Schüller-Christian, que era definida por uma tríade englobando lesões líticas no crânio, exoftalmia e diabete insípi$\mathrm{do}^{(1)}$. Atualmente, as diferentes formas da HCL são consideradas como uma única desordem da infância que afeta ossos, órgãos parenquimatosos e pele, com espectro clínico de diferentes apresentações, variando desde uma lesão óssea solitária, o GE, até a forma mais agressiva com disfunção multisistêmica (Letterer-Siwe) ${ }^{(2)}$.

Apesar da genérica denominação, HCL ser recomendada por alguns autores para nomear todo o espectro de apresentações clínicas das histiocitoses de células de Langerhans ${ }^{(2-3)}$, a expressão "granuloma eosinofílico" (GE) é amplamente utilizada para designar quadros de HCL formados por lesões ósseas localizadas ${ }^{(4-6)}$.

A maioria dos pacientes com GE apresenta envolvimento da cabeça e pescoço, sendo a órbita um local de freqüente manifestação e com possibilidades terapêuticas variadas ${ }^{(7)}$. O objetivo do presente trabalho é descrever um caso raro de GE que regrediu após biópsia incisional e rever a literatura sobre essa curiosa entidade. 
DESCRIÇ̃̃O DO CASO

Um adolescente de 17 anos do sexo masculino foi encaminhado ao setor de oculoplástica do HCFMRP-USP com história de edema e nodulação em pálpebra superior esquerda associados à dor local há 1 mês. Ele havia feito uso de antiinflamatórios não hormonais sem orientação médica e sem melhora clínica.

Ao exame físico notava-se na pálpebra superior do olho esquerdo nódulo de aproximadamente $2 \mathrm{~cm}$ de diâmetro com evidentes sinais flogísticos (figura 1A). Foi feito diagnóstico presuntivo de abscesso palpebral e realizada drenagem cirúrgica ambulatorial que possibilitou a saída de pequena quantidade de material seropurulento. Dois dias após, o paciente retornou ao serviço com piora do quadro de edema e dor local. Havia restrição à supraducção e a acuidade visual no olho afetado era de 20/50.

A tomografia computadorizada de órbitas evidenciou lesão expansiva na porção superior da órbita esquerda, com grande erosão óssea, destruição quase total do teto da órbita e extensão para a fossa craniana anterior. Notava-se também edema de partes moles periorbitário e deslocamento inferior do globo ocular esquerdo (figura 1B). O paciente foi então submetido à biópsia incisional, via palpebral, sob narcose.

$\mathrm{O}$ exame histopatológico mostrou uma infiltração predominante de histiócitos, apresentando núcleos ovalados ou reniformes e positivos pela imuno-histoquímica, para proteína S-100 (figura 2). Após a biópsia houve melhora clínica progressiva do quadro (figura 3A), já notada no décimo dia pós-operatório. Sem que nenhum outro tratamento fosse instituído, uma tomografia computadorizada de órbitas, realizada 22 meses após a biópsia, não evidenciou nenhuma lesão intra-orbitária e mostrou completa regeneração do teto da órbita esquerda (figura 3B).

\section{DISCUSSÃO}

O caso descrito expõe alguns aspectos relevantes do diagnóstico e tratamento do GE, que é uma entidade importante, pois, embora de ocorrência rara, ela interessa várias especialidades médicas além da oftalmologia.

Apesar do GE ser descrito como uma afecção da infância ele pode aparecer em raros casos até aos 65 anos de idade ${ }^{(8)}$. No presente caso, a idade de apresentação está condizente com a faixa etária verificada em outros trabalhos $(17 \text { anos })^{(9-12)}$. $\mathrm{Na}$ órbita, o GE acomete, principalmente, os ossos esfenóide e frontal (paredes lateral e superior).

Como no caso em questão, ele se manifesta clinicamente mimetizando quadros de celulite orbitária com manifestações agudas ou crônicas. Assim, na presença de uma lesão inflamatória orbitária da infância, o GE deve sempre ser lembrado em virtude das peculiaridades envolvidas no seu diagnóstico e tratamento. Na tomografia computadorizada o GE aparece como uma massa de densidade semelhante à da musculatura, com reforço após contraste e sinais de lise óssea de aspecto irregular, tamanho variável e sem sinais de esclerose ${ }^{(13)}$.

Histopatologicamente, ele apresenta-se como um granuloma composto por linfócitos, eosinófilos e células de Langerhans, as quais são caracterizadas por núcleo indentado (aspecto reniforme) e moderada quantidade de citoplasma. À microscopia eletrônica pode ser demonstrada a presença dos característicos grânulos de Birbeck e a imunohistoquímica mostra positividade para marcadores celulares CD1 a e S-100, sendo estes de valor fundamental no diagnóstico ${ }^{(2)}$, tal qual ocorreu no caso apresentado.

Além da importância do diagnóstico, o manejo no tratamento é fundamental. As principais formas de tratamento envolvem quimioterapia, radioterapia, excisão cirúrgica e injeção local de corticosteróides ${ }^{(6,9,12,14)}$.

Apesar do tratamento do GE orbitário ser pouco discutido na literatura, (25 casos nos últimos 20 anos nos bancos de dados Medline e Probe/Elsevier), a evolução parece ser benigna nos casos estritamente unifocais de origem óssea, mas também em alguns casos que se originam de tecidos moles $^{(5-6,8-9,91-12,14)}$. Nesse sentido, a discussão a respeito da melhor conduta se baseia em fatores de risco locais e sistêmicos. Localmente, o risco de complicações cirúrgicas e os
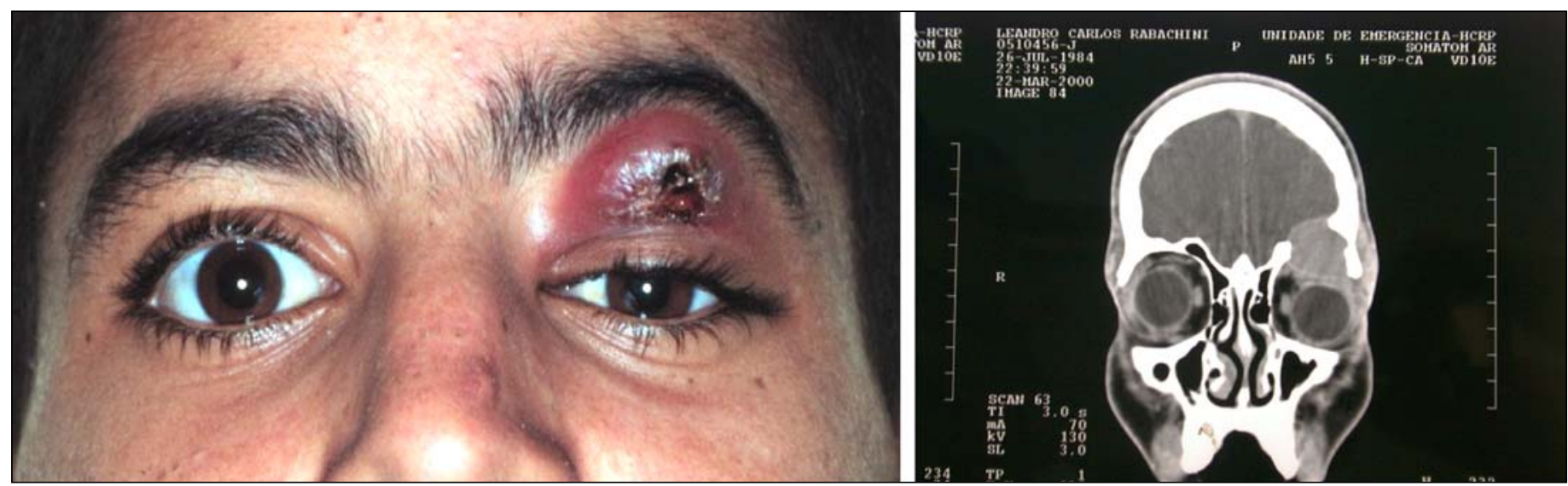

Figura 1 - A: Apresentação do caso. Notar importante edema e hiperemia de pálpebra superior esquerda, simulando celulite pré-septal; B. Tomografia computadorizada de órbitas mostrando extensa massa com erosão do teto da órbita esquerda se estendendo até a fossa craniana anterior 


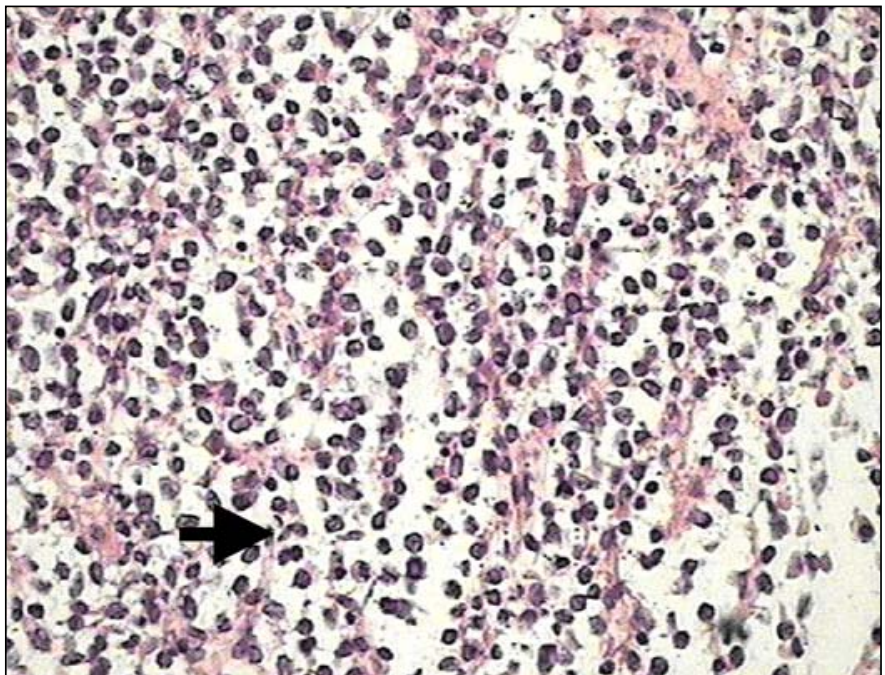

Figura 2 - Infiltração predominante de histiócitos, apresentando núcleos ovalados ou reniformes (seta) (Hematoxilina \& Eosina, X 200), à esquerda. Notar em maior aumento detalhes dos núcleos dos histiócitos (Hematoxilina \& Eosina, X 400), à direita

implicados na radioterapia (lesão de nervo óptico, dentre outras) devem ser bem avaliados. Do ponto de vista sistêmico, há de se levar em conta as complicações da imunodepressão com quimioterápicos e corticosteróide.

Dessa maneira, a ocorrência, como no presente caso, de lesões com remissão espontânea após biópsia ${ }^{(5)}$ e curetagem local $^{(9)}$ abre novas perspectivas terapêuticas. Apesar de não haver confirmação patogênica, pode-se aventar a hipótese de que uma pequena desorganização na estrutura do granuloma, tal qual a efetuada por uma biópsia, venha desencadear grande destruição da massa e estímulo para regeneração e cicatrização óssea.
Portanto, biópsia incisional com ou sem injeção de esteróides, seguida de criteriosa observação com rotineiros exames de imagem (tomografia computadorizada), deve ser a primeira opção de tratamento nas formas unifocais de GE orbitário. Se por acaso após a biópsia, houver aumento do granuloma ou mesmo aparecimento de outras lesões, medidas mais enérgicas, incluindo radio e quimioterapia, devem ser empregadas.

\section{AB S T RAC T}

Purpose: To report a case of a 17-year-old patient who presented with spontaneuos remission of an eosinophilic granuloma (EG) of the superior orbital wall after biopsy. Methods: Case report. Results: An orbital roof lesion was biopsied through lid crease approach. The histopathological study showed a granuloma with a proliferative aspect with macrophages, eosinophils and Langerhans' cells, without neoplastic features. After biopsy there was spontaneous remission demonstrated by computerized tomography scans of the orbit on a 22-month follow-up period. Conclusion: This case highlights that spontaneous remission of unifocal eosinophilic granuloma should be considered in the management of these lesions.

Keywords: Eosinophilic granuloma; Histiocytosis; Langerhans cell; Orbital disease/pathology; Biopsy; Case report; Adolescent

REFERÊNCIAS

1. Lichtenstein L. Histiocytosis X: integration of eosinophilic granuloma of bone, Letterer-Siwe disease and Shuller-Christian disease as a single nosologic entity. Arch Pathol 1953;56:84-102.

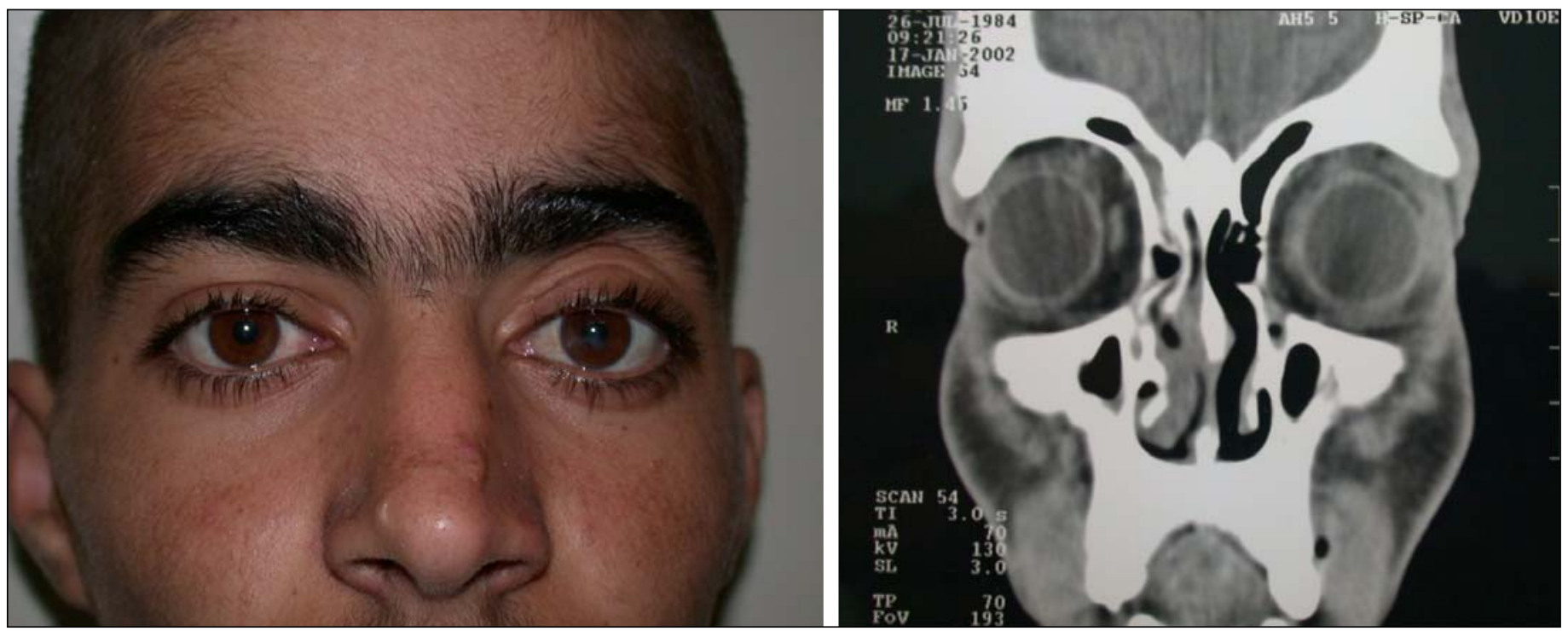

Figura 3 - A: Aspecto do paciente após 22 meses de seguimento. Notar recuperação da lesão palpebral, cuja única seqüela é a atrofia da gordura orbitária superior; B: Tomografia computadorizada de órbitas após 22 meses da biópsia mostrando completa regeneração óssea no local, com desaparecimento da lesão do teto da órbita esquerda 
2. Bergmann M, Yan Y, Brück W, Palm KV, Rohkamm R. Solitary Langerhans cell histiocytosis lesion of the parieto-occipital lobe: a case report and review of the literature. Clin Neurol Neurosurg 1997;99:50-5.

3. Sellari-Franceschini S, Forli F, Pierini S, Favre C, Berrettini S, Macchia PA. Langerhans' cells histiocytosis. Int J Pediatr Otorhinolaryngol 1999; 48:83-7.

4. Zausinger S, Muller A, Bise K, Klauss V. Eosinophilic granuloma of the orbit in an adult woman. Acta Neurochir (Wien) 2000;142:215-7.

5. Glover AT, Grove AS. Eosinophilic granuloma of the orbit with spontaneous healing. Ophthalmology 1987;94:1008-12.

6. Ghazi I, Philippe J, Portas M, Bergue A, Patte C, Bonsch M. Solitary eosinophilic granuloma of the external wall of the orbit. J Fr Ophthalmol 1991;14:189-94.

7. Quraishi MS, Blayney AW, Walker D, Breatnach FB, Bradley PJ. Langerhans' cell histiocytosis: head and neck manifestations in children. Head Neck 1995; 17:226-31.
8. Amemiya T. Eosinophilic granuloma of the soft tissue in the orbit. Ophthalmologica 1981;182:42-8.

9. Feldman RB, Moore DM, Hood CI, Hiles DA, Romano PE. Solitary eosinophilic granuloma of the lateral orbital wall. Am J Ophthalmol 1985;100:318-23.

10. Nover A, Ohmer B. Eosinophilic granuloma of the orbit. Klin Monatsbl Augenheilkd 1977;171:283-6.

11. Baghdassarian SA, Shammas HF. Eosinophilic granuloma of orbit. Ann Ophthalmol 1977;9:1247-51.

12. Jakobiec FA, Trokel SL, Aron-Rosa D, Iwamoto T, Doyon D. Localized eosinophilic granuloma (Langerhans' cell histiocytosis) of the orbital frontal bone. Arch Ophthalmol 1980;98:1814-20.

13. Sanchez R, Weber AL, Alexander A, Sweriduk S, Vici G. Paraorbital lesions. Eur J Radiol 1996;22:53-67.

14. Wirtschafter JD, Nesbit M, Anderson P, McClain K. Intralesional methylprednisolone for Langerhans' cell histiocytosis of the orbit and cranium. J Pediatr Ophthalmol Strabismus 1987;24:194-7.

\title{
Encontro Anual da Academia Americana de Oftalmologia
}

\author{
14 a 18 de novembro de 2.003
}

\section{Centro de Convenções de Anaheim \\ CALIFORNIA - EUA}

INFORMAÇÕES: E-mail: meetings@aao.org

Home page: www.aao.org 